CORPORATE REBRANDING FRAMEWORK BY CGV CINEMAS

\title{
CORPORATE REBRANDING FRAMEWORK OLEH CGV CINEMAS
}

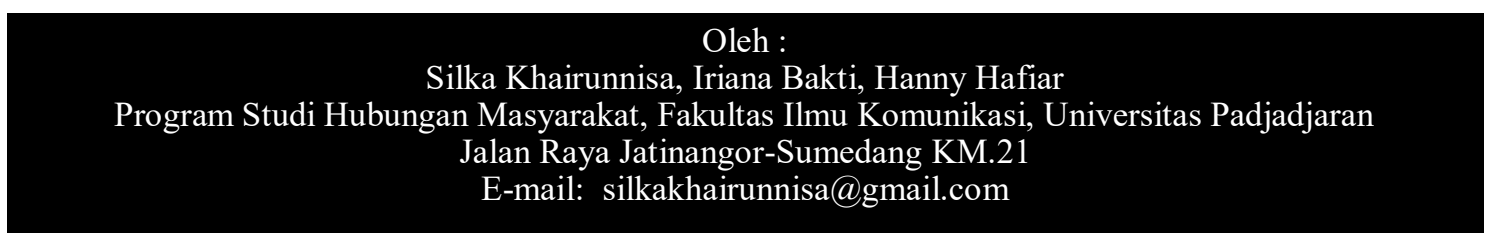

Abstract. The purpose of research are to determine the stages of analysis, planning and evaluation of corporate rebranding framework of CGV Blitz to be CGV Cinemas. This research uses descriptive method with qualitative data type. Data collection method used in this research is interview, observation, and literature study. The results of this research showed that CGV Cinemas has been rebranding but in reality there are still many stakeholders from CGV Cinemas that targeted for rebranding that still not aware of the rebranding of CGV Blitz to CGV Cinemas by doing three stages of analysis, planning and evaluation. In this study concluded that at the analysis stage, planning and evaluation, communication campaign that CGV Cinemas do to internal customer has not been able to optimally because there's still employee that did not undetstand with CGV Cinemas concept and still miscalled the old brand.At the evaluation stage, CGV Cinemas are not doing an evaluation after communication campaign and only doing an evaluation at the time of execution of socialization in the form of question and answers and CGV Cinemas are doing evaluation in focus group discussion to some customers but those evaluation was evaluation non formal and not spread and did not have a structured results that's why those evaluation could not be used as a measure of success while doing or after doing a rebranding to customers.

Keywords: CGV Cinemas, corporate rebranding framework, rebranding

Abstrak. Penelitian ini bertujuan untuk mengetahui bagaimana tahapan analisis, perencanaan dan evaluasi corporate rebranding framework CGV Blitz menjadi CGV Cinemas. Penelitian ini menggunakan metode deskriptif dengan jenis data kualitatif. Metode pengumpulan data yang digunakan dalam penelitian ini adalah wawancara, observasi, dan studi pustaka. Hasil penelitian ini menunjukkan bahwa CGV Cinemas sudah melakukan rebranding namun pada kenyataannya masih banyak stakeholders dari CGV Cinemas yang menjadi target untuk rebranding yang masih tidak mengetahui adanya rebranding CGV Blitz menjadi CGV Cinemas dengan melakukan tiga tahapan yaitu tahapan analisis, perencanaan dan evaluasi. Dalam penelitian ini disimpulkan bahwa pada tahap analisis, perencanaan dan evaluasi, communication campaign yang CGV Cinemas lakukan ke internal customer masih belum optimal dikarenakan, masih ada karyawan yang belum paham dengan konsep CGV Cinemas dan masih salah menyebut merek lamanya dan CGV Cinemas tidak mengadakan evaluasi sesudah mengadakan kampanye komunikasi dan hanya melakukan evaluasi pada saat pelaksanaaan sosialisasi dalam bentuk tanya jawab dan CGV Cinemas melakukan evaluasi focus group discussion ke beberapa customer namun evaluasi tersebut merupakan evaluasi non formal dan tidak menyeluruh serta tidak mempunyai hasil yang terstruktur maka dari itu evaluasi tersebut tidak dapat dijadikan ukuran keberhasilan saat melakukan maupun sesudah melakukan rebranding terhadap customer.

Kata kunci : CGV Cinemas, corporate rebranding framework, rebranding

\section{A. PENDAHULUAN}

Brand merupakan identitas perusahaan yang tentunya dapat mempengaruhi penilaian masyarakat dalam membeli produk. Salah satu upaya yang dapat dilakukan perusahaan dalam melakukan inovasi brand adalah dengan melakukan rebranding. Rebranding merupakan upaya yang dilakukan oleh perusahaan untuk mengubah total atau 
memperbaharui sebuah brand yang telah ada.

Pada bulan Januari 2016, daftar negatif investasi telah dirilis dan bidang usaha bioskop sekarang terbuka sepenuhnya untuk penanaman modal asing. Maka dari itu tidak dipungkiri jika ke depannya akan ada banyak bisnis bioskop yang memasuki industri hiburan di Indonesia .

Maka dari itu PT.Graha Layar Prima, Tbk yang merupakan perusahaan bergerak di bidang hiburan dengan format layar lebar yang dibuka pada bulan Oktober tahun 2006 dengan nama Blitz Megaplex yang dulunya memiliki konsep One entertainment center pada bulan April 2014 Blitz Megaplex melakukan pencatatan saham perdana di Bursa Efek Indonesia yang kemudian mayoritas dimiliki oleh investor asing asal Korea Selatan CJ CGV Co. Ltd. Dengan diakuisisinya saham Blitz Megaplex oleh CJ $\mathrm{CGV}$, maka perusahaan Korea ini berusaha untuk memasukkan corporate identity CGV ke Blitz Megaplex yang berubah menjadi CGV Blitz lalu pada awal tahun 2017 tanggal 11 Januari CGV Blitz melakukan rebranding kembali menjadi CGV Cinemas.

"Tujuan rebranding adalah sebagai bentuk memperkuat identitas "CGV" dan juga aktualisasi konsolidasi PT Graha Layar Prima Tbk, dan CJ
CGV. “

Dengan dilakukannya rebranding menjadi CGV Cinemas melalui konsolidasi tersebut, CGV Cinemas berharap dapat memanfaatkan corporate identity dari CGV Cinemas tersebut yang sudah dikenal global serta memanfaatkan teknologi-teknologi terbaru dari $\mathrm{CGV}$ Cinemas. Berikut hasil wawancara dengan Wisnu Triatmojo selaku Countryhead Brand Marketing CGV Cinemas:

"Perubahan nama ini juga memanfaatkan CGV yang dikenal baik secara global juga bentuk inovasi produk teknologi dan lainnya kepada pelanggan."

CGV Cinemas membutuhkan strategi yang baru, agar image bioskop tidak selalu identik dengan menonton film saja. Maka dari itu PT. Graha Layar Prima dan CJ CGV melakukan rebranding kembali dari CGV Blitz menjadi CGV Cinemas.

Meskipun CGV Cinemas sudah melakukan rebranding namun kenyataannya masih banyak stakeholders dari CGV Cinemas yang menjadi target untuk rebranding tidak mengetahui adanya rebranding CGV Blitz menjadi CGV Cinemas dan masih ada stakeholder internal yaitu karyawan CGV Cinemas sendiri yang masih salah menyebut CGV menjadi Blitz. Berikut adalah pernyataan Audrrey Safira selaku media rela- 
tions CGV Cinemas dari hasil wawancara berikut:

"Jadi berdasarkan sepengetahuan kami masih ada customer yang selalu mengidentikkan kita dengan blitz padahal kita udah rebranding dari januari kemarin"

Seperti ungkapan yang dikemukakan di atas, hal tersebut menggambarkan meskipun sudah melakukan rebranding namun awareness mengenai corporate identity CGV Cinemas masih kurang diketahui oleh stakeholder internal dan external.

Berkaca dengan rebranding yang dilakukan CGV Cinemas melakukan upaya melalui beberapa tahap dalam melakukan rebranding menjadi CGV Cinemas. Salah satunya adalah melalui corporate rebranding framework yang akan membantu perusahaan untuk meningkatkan stakeholder awareness perusahaan.

Corporate rebranding framework yang dilakukan oleh CGV Cinemas dilatar belakangi dengan dasar yang jelas, selain untuk menaikkan citra perusahaan dan mengubah identitas menjadi lebih baik tentunya untuk menaikkan awareness serta menaikkan standar fitur-fitur bioskop atau disebut dengan upgrading process. Menurut Daly dan Moloney (2003:34) rebranding perusahaan terdiri dari tiga tahapan, yaitu analisis, perencanaan, dan evaluasi.
Berbagai tahapan rebranding di $\mathrm{CGV}$ Cinemas telah dilaksanakan sejak awal tahun 2017. Namun, tahapan corporate rebranding yang dilakukan masih belum optimal dalam membangun awareness corporate identity CGV. Hal ini dapat dilihat dari belum terpenuhinya beberapa tahapan kegiatan rebranding yang tidak sesuai dengan konsep Daly dan Moloney (2003:34).

Permasalahan yang ditemukan yaitu mulai dari communication campaign, meskipun CGV Cinemas melakukan communication campaign melalui sosialisasi namun sosialiasi tersebut tidak dilakukan secara spesifik dimana CGV Cinemas hanya melakukan sosialisasi melalui perwakilan dari beberapa cabang namun CGV Cinemas tidak melakukan sosialisasi menyeluruh ke seluruh karyawan CGV Cinemas, pernyataan ini diungkapkan oleh Diana Abbas selaku Head of Operation CGV Cinemas. Berikut hasil wawancaranya dengan Diana Abbas:

"Biasanya kita sosialisasi dulu karena ada beberapa lokasi yang di rebranding jadi kita kita meeting ke perwakilan karyawan"

Meskipun sudah melakukan sosialisasi, namun sosialisasi ini hanya diwakilkan oleh beberapa perwakilan di setiap sites bioskop CGV Cinemas sehingga masih ada beberapa karyawan 
CGV Cinemas yang masih salah menyebut merek lamanya Pernyataan ini diungkapkan oleh Wisnu Triatmojo selaku Countryhead Brand Marketing CGV Cinemas, berikut hasil wawancaranya:

"Yah masih banyak banget yang nyebut blitz, padahal konsep CGV sama Blitz jauh banget, kita mau mengubah perception itu."

Permasalahan lainnya terkait dengan perencanaan di dalam corporate rebranding framework adalah dalam menentukan rebranding marketing plan, dimana elemen mix dari rebranding marketing plan seperti pricing, product benefit, product range dan integrated communication dilakukan dengan terpisah dimana pricing, product benefit dan product range ditentukan oleh pihak perusahaan Korea yaitu CJ Group dan integrated communication ditentukan oleh rebranding task force CGV Cinemas Indonesia.

Berikut pernyataan dari Diana Abbas selaku Head of Operation CGV Cinemas:

"elemen product benefit, pricing atau rebranding marketing plan bukan urusan kita, kita ngikut SOP perusahaan koreanya kalo integrated communication kita yang arrange"

Padahal di dalam konsep Daly \& Moloney (34:2004), elemen mix dari rebranding marketing plan berdasarkan teori dan kebijakan dari marketing di- mana elemen mix dari marketing sendiri merupakan kerangka yang tidak dapat dipisahkan.

Lalu selanjutnya pada tahap evaluasi ditemukan bahwa CGV Cinemas tidak mengadakan evaluasi sesudah mengadakan kampanye komunikasi dan hanya melakukan evaluasi pada saat pelaksanaaan sosialisasi dalam bentuk tanya jawab sehingga belum sesuai dengan konsep Daly \& Moloney (2004:35) dimana pada tahap evaluasi kampanye komunikasi seharusnya dilakukan sepanjang proses kampanye komunikasi tidak hanya pada saat pelaksanaan saja. Berikut pernyataan dari Maya Monissa selaku Senior Headcount Acquisition.

"Untuk evaluasi kita sekedar evaluasi tanya jawab setiap kita melakukan sosialisasi terkait rebranding kita gak ngelakuin evaluasi setelah kampanye komunikasi"

Dan pada tahap evaluasi terhadap customer, CGV Cinemas melakukan evaluasi fgd ke beberapa customer namun evaluasi tersebut merupakan evaluasi non formal dan tidak menyeluruh serta tidak mempunyai hasil yang terstruktur maka dari itu evaluasi tersebut tidak dapat dijadikan ukuran keberhasilan saat melakukan maupun sesudah melakukan rebranding terhadap customer. Berikut adalah hasil wawancara dari Diana Abbas selaku Head of Operation Planning 


\section{\& Support CGV Cinemas:}

"Evaluasi ke customer kita ngadainnya focus group discussion bareng sama divisi human resource ini sih ga formal jatuhnya curious aja"

Berdasarkan pemaparan diatas, dapat disimpulkan bahwa terdapat sejumlah permasalahan yang ditemukan saat melakukan wawancara bahwa corporate rebranding framework $\mathrm{CGV}$ Cinemas masih belum optimal dan belum sesuai dengan konsep corporate rebranding framework yang meliputi tahap analisis, perencanaan dan evaluasi yang dikemukakan oleh Daly dan Moloney dalam jurnalnya yang berjudul Irish Marketing Review volume 17 number $1 \& 2$ tahun 2004.

Peneliti merasa tertarik untuk melakukan penelitian ini karena corporate rebranding framework sebuah perusahaan format layar lebar masih jarang dilakukan mengingat hanya ada sedikit perusahaan format layar lebar di Indonesia dan juga bagaimana merek "CGV" meskipun sudah dikenal di beberapa negara namun merek "CGV" ini masih kurang dikenal stakeholders CGV Cinemas di Indonesia. Untuk itu peneliti ingin meneliti serangkaian tahapan "Corporate Rebranding Framework oleh CGV Cinemas"
Penelitian ini menggunakan paradigma positivisme. Peneliti menggunakan paradigma positivisme dalam penelitian dikarenakan peneliti ingin mengetahui corporate rebranding framework yang dilakukan oleh CGV Cinemas. Menurut (Gunawan, 2015: 47) paradigma positivisme berorientasi pada:

“...upaya mempertahankan status quo dari penelitian yang ada dengan maksud penelitian dilakukan dengan asumsi isu sosial sudah ada di luar ..."

Metode yang digunakan dalam penelitian ini adalah metode deskriptif. Metode deskriptif adalah penelitian yang hanya memaparkan situasi atau peristiwa. Mereka menyebut metode yang "melulu" deskriptif sebagai penelitian survey (Isaac dan Michael) atau penelitian observasional (Wood (dalam Rakhmat, 2009:24-25)

Dalam penelitian ini subjek ditentukan dengan teknik sampling nonprobability, purposive sampling dimana mengambil sumber data dengan pertimbangan misalnya orang yang dianggap paling tahu. (Sugiyono, 2012:219)

Teknik validitas data yang peneliti gunakan dalam penelitian ini adalah triangulasi. Triangulasi yang dimaksud adalah triangulasi sumber data. Triangulasi diartikan sebagai teknik pengumpulan data yang bersifat menggabungkan 
dari berbagai teknik pengumpulan data dan sumber data yang telah ada. (Sugiyono, 2009:83)

\section{B. HASIL DAN PEMBAHASAN}

Tahapan awal yang dilakukan dalam corporate rebranding framework yaitu tahapan analisis. Sebelum melakukan rebranding, suatu perusahaan harus memiliki alasan-alasan atau dasar yang kuat dalam melatarbelakangi untuk merencanakan atau menentukan suatu program.

Pada analisis situasi, CGV Cinemas melakukan analisis situasi dengan menentukan market analysis yang menghasilkan tiga bagian analisis pasar yang didapatkan berdasarkan survey yang diakukan oleh tim Rebranding Task Force dan menghasilkan tiga tahapan yaitu service equipment, customer experience dan brand communication yang mempunyai tujuan yang berbeda-beda.

Hal ini sesuai dengan pernyataan Daly dan Moloney (2004:34) dalam corporate rebranding framework bahwa pada analisis pasar yang terdapat di dalam tahapan analisis, suatu perencanaan marketing harus dikembangkan dari situasi atau market analysis.

Hal ini juga diperkuat oleh Brown (2008:12) bahwa analisis pasar merupakan studi ilmiah dari pasar atau metode marketing untuk produk yang spesifik atau servis, merupakan hasil yang digunakan sebagai dasar kebijakan, perencanaan dan operasi dari perusahaan.

Sebaiknya menurut peneliti, analisis pasar menggunakan dan mempertahankan dengan menentukan dan menganalisis segmentasi customer yang dituju ke dalam tahapan analisis pasar dari CGV Cinemas sesuai dengan jasa yang ditawarkan.

Lalu pada bagian brand audit, $\mathrm{CGV}$ Cinemas mengadakan brand audit dalam bentuk SWOT (Strength, Weakness, Opportunities, Threats).

Hal ini sudah sesuai dengan pernyataan Daly dan Moloney yang mengatakan bahwa: "Specifically brand audits should provide the market's perspective on the brands showing the strength and weakness and those competing brands.” (Daly \& Moloney, 2004:34)

Hal ini juga diperkuat oleh Parente \& Hutchinson (2015:42) bahwa audit merek, seperti SWOT adalah cara lain untuk informasi latar belakang. dan juga dilihat dari kepribadian, ekuitas, evolusi merek. Berikut pernyataannya:

"A brand audit, like SWOT is another way of background information. The emphasis include a look at the brand personality, equity, evolution" (Parente \& Hutchinson, 
2015:42)

Dalam meningkatkan brand audit, selain melakukan SWOT, menurut peneliti perusahaan dapat meningkatkan brand audit dengan mengevaluasi penilaian pada konsumen serta memberikan profil yang rinci terkait merek yang baru.

Sesudah itu, dilanjutkan dengan poin identifikasi peluang yang dilakukan oleh CGV Cinemas dapat menguntungkan antar kedua perusahaan yaitu PT. Graha Layar Prima dan CJ CGV dimana keduanya mempunyai nama dan posisi yang kuat di dunia bioskop sehingga dapat saling menguntungkan.

Dalam dunia bisnis kerjasama tersebut tentunya dapat melahirkan win-win solution hal ini sesuai dengan konsep Daly \& Moloney (2004:35) terdapat tahap opportunity identification atau identifikasi peluang dalam analisis yang berada di dalam corporate rebanding framework.

Berikut pernyataan dari bapak Hendro Djasmoro selaku Creative Strategist di Talikama Communication terkait identifikasi peluang:

"definisi identifikasi peluang gimana perusahaan see the opportunity in the market and bisa manfaatin peluangnya biar mereka mendapatkan

\section{profitability"}

Sebaiknya identifikasi peluang ini dipertahankan dengan cara meninjau kembali identifikasi peluang yang sudah dilakukan dengan mengevaluasi peluang agar lebih optimal dengan peluang yang ada. Pernyataan ini diperkuat oleh (Hisrich, Peters \& Shepherd, 2008:14) yang menyatakan bahwa ketika peluang diidentifikasi menggunakan masukan dari pelanggan, asosiasi bisnis, penyalur, atau orang teknis, maka setiap peluang ditinjau dan dievaluasi.

Pada tahap selanjutnya yaitu retain and support, CGV Cinemas mengidentifikasi elemen dari merek perusahaan yang dapat dipertahankan permanen dan CGV Cinemas mempertahankan elemen merek dari konsep cultureplex yang mereka aplikasikan semenjak mereka melakukan rebranding pertama mereka dari Blitz Megaplex menjadi CGV Blitz. Serta mempertahankan brand outlook untuk sites nya dengan desain retro vintage.

Selain mengidentifikasi elemen merek untuk dijadikan permanen, $\mathrm{CGV}$ Cinemas juga mempertahankan elemen merek mereka untuk sementara dengan mempertahankan salah satu product nya untuk sementara berupa feature bioskop yang baru dibuka pada tahun 2017 yaitu feature bioskop Satin Suites dan Sphere 
$X$ dan melihat bagaimana reaksi customer dan perkembangan dari bioskop tersebut.

\section{Pemahaman CGV Cinemas mengenai} retain and support dalam corporate rebranding framework dari (Daly \& Moloney, 2004:35) sudah sesuai dengan fungsi dari retain and support yaitu untuk mengidentifikasi elemen merek untuk dirawat secara permanen dan juga pada poin kedua adalah untuk mengidentifikasi elemen merek untuk dipertahankan untuk sementara.

Hal ini juga diperkuat oleh (Susanto \& Wijarnako, 2004:15) bahwa merek memberikan gambaran mengenai posisi yang ditargetkan mencakup manfaat, pengembangan kepribadian, lingkup merek, dan segmen yang menjadi target.

Peneliti menyarankan agar retain and support dapat dipertahankan dengan menguatkan brand image dari elemen merek yang sudah ditentukan tersebut agar dapat meningkatkkan loyalitas konsumen terhadap brand tersebut. Brand image tersebut dapat dipertahankan dengan memperbanyak acara membuat film, atau acara komunitas untuk pecinta film sesuai dengan segmentasi pilihan film CGV Cinemas atau memberi promosi atau kuis yang berhadiah merchandise yang menggunakan logo CGV Cinemas agar dapat menguatkan citra merek. Pernyataan ini diperkuat oleh (Setiadi, 2003:180) bahwa

"Citra terhadap merek berhubungan dengan sikap yang berupa keyakinan dan preferensi terhadap suatu merek."

Jika elemen merek diperkuat dengan membangun brand image dengan langkah -langkah tersebut tentunya akan ada banyak manfaat yang didapatkan perusahaan seperti lebih mudah mendapatkan loyalitas consumer dan juga memberikan daya tarik tersendiri bagi consumer.

Pada tahap selanjutnya dari corporate rebranding framework adalah neutralise, CGV Cinemas melakukan tahapan neutralise ini dengan menghilangkan elemen merek logo lamanya yang bertulisan CGV Blitz dan menggantinya menjadi CGV Cinemas pada awal tahun 2017 serta menghilangkan elemen merek seragam industrial dan menggantinya dengan seragam casual untuk menciptakan pengalaman dan kesan yang sama dengan CGV Cinemas di negara-negara lainnya.

Hal ini sudah sesuai dengan corporate rebranding framework dari Daly dan Moloney (2004:35) dimana tahap neutralise adalah untuk mengidentifikasi elemen merek apa saja yang dapat dihilangkan oleh perusahaan dalam melakukan corporate rebranding frame- 
work. Sebaiknya menurut peneliti tahapan neutralise dapat dipertahankan dengan cara membuat program brand revitalisasi agar dapat memprioritas tujuan dari revitalisasi elemen merek tersebut.

Pernyataan ini diperkuat juga oleh Kotler \& Keller (2009:356) dimana revitalisasi merek perlu dilakukan mengingat terjadinya perubahan selera dan preferensi konsumen, kemunculan pesaing baru/teknologi baru.

Setelah itu pada tahap terakhir dari analisis, adalah new brand decision, pada tahap ini, tim rebranding task force dan top management mengambil keputusan bersama dan menyepakati untuk menjadikan merek CGV Cinemas brand identity yang baru.

Hal ini sudah sesuai dengan tahap terakhir dari analysis yang berada di dalam corporate rebranding framework Daly \& Moloney (2004:35) yang terdapat new brand decision setelah melakukan berbagai tahap situation analysis, retain and support, dan neutralise. Daly \& Moloney (2004:30) menyatakan bahwa merek lebih dari sebuah nama dan perwujudan fisiologis dari nama itu Sebuah merek memiliki arti bagi semua pemangku kepentingan.

Sebaiknya, menurut peneliti new brand decision dipertahankan dan ditingkatkan dengan cara memperkuat positioning merek baru CGV Cinemas tersebut karena positioning berperan penting untuk meningkatkan kesadaran di benak pelanggan maupun karyawan. Pernyataan ini diperkuat oleh Kartajaya (2010:19) bahwa positioning merupakan proses menempatkan keberadaan perusahaan di benak pelanggan dengan membangun kepercayaan, keyakinan dan trust kepada pelanggan.

Positioning ini dapat dilakukan dengan melakukan point-of-difference dengan mengunggulkan misal fitur bioskop yang baru Menurut Sari (2017:231) point-of-difference merupakan atribut yang konsumen hubungkan sangat kuat dengan merek tersebut. Keunikan asosiasi merek yang dirasakan.

Lalu pada tahap selanjutnya yaitu tahap perencanaan (planning) Pada tahap planning (perencanaan), ada beberapa poin yang harus diperhatikan menurut Daly \& Moloney (2004: 35), yaitu pertama, target audience kedua, external customernya dan strategi renaming serta bagaimana CGV Cinemas melakukan rebranding marketing plan.

Seperti pada tahap pertama, CGV Cinemas mengidentifikasi target audiens secara internal maupun external dan 
mengidentifikasi siapa yang menjadi target audiens untuk rebranding yaitu stakeholder external dan stakeholder internal. Target audiens external customer adalah customer, komunitas, media dan masyarakat sekitar perusahaan. Lalu pada tahap internal dari hasil identifikasi yang dilakukan adalah top management, middle management dan low management.

Hal ini sesuai dengan pernyataan Daly \& Moloney (2004: 35) dalam tahap target audience dimana pada tahap target audience, harus mengidentifikasi siapa audiens dari target external dan internal untuk rebranding campaign.

Identifikasi target audience ini dapat dipertahankan dengan cara mengidentifikasi siapa target audiens dari goals yang ingin dicapai.

Hal ini juga diperkuat oleh Kelly \& Jugenheimer (2008:59) Hal ini diungkapkan dalam pendapat berikut:

"Arriving at right target audience appears on the surface to be a simple exercise to get the most o of your marketing budget"

Menurut Kasali (2003:63) Stakeholder terbagi menjadi dua yaitu stakeholder internal dan stakeholder eksternal. Stakeholders internal adalah stakeholders yang berada di dalam lingkungan organisasi. Sedangkan stakeholder eksternal antara lain adalah konsumen.

Lalu pada tahap external customer terdapat poin renaming strategy dimana perusahaan menentukan renaming strategy apa yang akan dilakukan dalam melakukan rebranding dimana terdapat beberapa pilihan yaitu interim/dual, prefix, substitution atau brand amalgamation. Berkenaan dengan renaming strategy, CGV Cinemas sudah sesuai dengan konsep dimana CGV Cinemas melakukan renaming strategy dengan melakukan interim/dual.

Renaming strategy ini dilakukan dimana pada tahun 2015 Blitz Megaplex melakukan rebranding menjadi $\mathrm{CGV}$ Blitz dikarenakan akuisisi antara PT Graha Layar Prima Tbk dan CJ CGV lalu pada awal tahun 2017 CGV Blitz melakukan rebranding kembali dan melakukan perubahan sepenuhnya menjadi CGV Cinemas.

Pernyataan ini sesuai dengan pernyataan Kapferer (1992) seperti dikutip Daly dan Maloney (2004, 31-32) Interim/ Dual merupakan sebuah nama yang digunakan ketika masa transisi sebelum nama baru resmi digunakan.

Dalam meningkatkan renaming strat$e g y$, ini akan lebih baik jika dipertahan- 
kan dengan cara memperkuat ekuitas nilai merek tersebut. Hal ini didukung oleh pernyataan Aaker (1997:24) bahwa ekuitas merek adalah seperangkat aset dan liabilitas merek yang berkaitan suatu merek, nama dan simbolnya, yang menambah atau mengurangi nilai.

Poin selanjutnya dalam tahap external customer yaitu rebranding marketing plan ditemukan bahwa CGV Cinemas yang menentukan elemen mix tidak melibatkan tim rebranding task force dan hanya melibatkan direksi dan perusahaan korea yaitu CJ CGV dalam membuat serta menentukan elemen mix rebranding marketing plan seperti product benefit, product range dan pricing. Tim rebranding task force hanya membantu mencarikan data-data yang dibutuhkan oleh CJ CGV dan membuat elemen mix integrated communication yang berada di dalam rebranding marketing plan. Sehingga elemen mix dari rebranding marketing plan dibuat terpisah.

Seperti yang dikatakan oleh Daly \& Moloney (2004:35) yang mengatakan bahwa setiap elemen campuran direncanakan untuk proyek rebranding. Keputusan harus dibuat tentang manfaat produk, rangkaian produk, harga, komunikasi terpadu.
Pada dasarnya elemen mix yang terdapat di dalam rebranding marketing plan tidak seharusnya dibuat terpisah maka dari itu hal ini belum sesuai dengan pernyataan Daly \& Moloney (2004:36) yang menyatakan rebranding marketing plan dibuat berdasarkan teori dan prinsip marketing. Meskipun seluruh elemen mix rebranding marketing plan sudah dilakukan namun sebaiknya menurut peneliti suatu elemen mix tidak dapat ditentukan dan dibuat secara terpisah-pisah agar lebih optimal karena elemen mix merupakan kerangka.

Hal tersebut juga diperkuat pendapat triangulator Bapak Hendro Djasmoro sebagai triangulator. Berikut adalah hasil wawancaranya:

"Rebranding marketing plan elemennya meskipun ada macam macam tapi tetep harus dilakukan bareng because each of the element was a combination"

Lalu pada poin product benefit, CGV Cinemas sudah melakukan poin yang terdapat di dalam rebranding marketing yang merupakan elemen mix dari konsep Daly \& Moloney. Product range yang disebut adalah feature bioskop baru dari CGV Cinemas yaitu Satin Suite dan ScreenX. 
Pada poin product benefit, peneliti menyarankan kelebihan produk ini dapat dipertahankan lebih baik lagi dengan memenuhi setiap kebutuhan consumer dan memenuhi ekspetasi terhadap product benefit yang ditawarkan oleh perusahaan. Maka dari itu perusahaan harus memberikan effort kepada customer CGV Cinemas terkait dengan product benefit yang ditawarkan dengan meningkatkan kualitas sehingga dapat meningkatkan nilai brand identity CGV Cinemas. Seperti yang dikatakan oleh Zheithalm et al dalam Ariani (2009:180), bahwa:

"Bukti fisik yaitu kemampuan perusahaan menunjukkan eksistensinya kepada pihak eksternal. Penampilan dan kemampuan sarana dan prasarana perusahaan yang dapat diandalkan."

Dengan meningkatkan kualitas dan kenyamanan dari bioskopnya tentunya akan membuat customer semakin betah dengan layanan yang maksimal serta kondisi fisik bioskop yang nyaman.

Selanjutnya pada poin integrated communication yang berada di dalam rebranding marketing plan, CGV Cinemas membaginya menjadi tiga tahapan pertama melalui below the line, above the line dan juga through the line. Hal ini sudah sesuai dengan pernyataan Daly \& Moloney (2004:35) bahwa dalam melakukan rebranding marketing plan harus menentukan keputusan melalui elemen mix seperti integrated communication.

Menurut Kotler dan Armstrong (2008:120) Integrated Communication merupakan proses mengintegrasikan dan mengkoordinasikan saluran komunikasi perusahaan untuk pesan yang jelas.

Peneliti menyarankan dalam mempertahankan konsep integrated communicaton yang ada, akan lebih optimal jika program integrated communication dibentuk strategi yang dapat diterapkan CGV Cinemas dengan melibatkan consumer seperti membuat iklan dimana CGV Cinemas meyakinkan konsumen bahwa mereka membutuhkan hiburan.

Pada poin pricing, CGV Cinemas sudah sesuai dengan konsep Daly \& Moloney (2004:35) dimana perusahaan harus menentukan elemen mix pricing pada rebranding marketing plan. Menurut Kotler \& Armstrong (2001:439) pricing atau harga adalah sejumlah uang yang dibebankan atas suatu produk atau jasa karena menggunakan produk atau jasa tersebut.

Karena CGV Cinemas sudah melakukan poin pricing sesuai dengan elemen mix dari rebranding marketing plan konsep Daly \& Moloney (2004:34) 
maka peneliti menyarankan perusahaan dapat mempertahankan elemen mix rebranding marketing plan ini dengan mengadakan harga promosi di awalawal pembukaan feature bioskop yang baru untuk ke depannya atau di acaraacara khusus.

Pada poin product range, CGV Cinemas menentukan product range nya yaitu Satin Suite dan ScreenX yang merupakan feature bioskop terbaru mereka. CGV Cinemas sudah melakukan kegiatan yang sesuai dengan konsep Daly \& Moloney (2004:35), dimana pada tahapan rebranding marketing plan terdapat elemen mix product range dalam perencanaan suatu proyek rebranding.

Sebaiknya perusahaan dapat meningkatkan product rangenya menjadi lebih variatif dengan bermacammacam feature bioskop yang sesuai dengan segmentasi masyarakat Indonesia misal membuat feature bioskop untuk anak-anak yang lebih kids friendly.

Selain itu, pernyataan ini juga diperkuat oleh Kotler dan Armstrong (2001:355) sebuah produk dapat ditawarkan dengan beraneka macam fitur. Perusahaan dapat menciptakan model dengan tingkat yang lebih tinggi dengan menambah beberapa fitur.
Setelah itu dilanjutkan dengan tahap internal customer, dimana pada tahap internal customer terdapat communication strategy dimana CGV Cinemas melakukan perencanaan untuk pelatihan dan kampanye komunikasi. Dijelaskan masih ada karyawan di lapangan yang masih menyebut merek lama blitz.

Bahkan ada yang tidak mengetahui konsep CGV Cinemas hal ini belum sesuai karena kampanye komunikasi harus dikembangkan baik secara komunikasi internal dan juga pelatihan. Konsep ini diberikan oleh Daly \& Moloney (2004:34) yang menjelaskan bahwa berkomunikasi dengan customer internal setelah menemukan sikap pelanggan internal, perusahaan harus mengembangkan program komunikasi dan pelatihan untuk mendapatkan dukungan dan komitmen karyawan.

Sebaiknya CGV Cinemas memanfaatkan media internal yang dipunyai dalam mengkomunikasikan kampanye rebranding kepada karyawan agar pesan yang dituju lebih optimal.

Selain mengadakan media internal melalui yang telah disebutkan di atas, CGV Cinemas dapat melakukan acara seperti gathering atau event dalam melakukan komunikasi secara langsung atau dalam bentuk lisan. Hal tersebut di- 
perkuat oleh triangulator Hendro Djasmoro yang menyatakan bahwa:

"Campaign internal kalo bentuk aktivasi akan lebih kena, bikin kontes yang berhubungan dengan cgv atau dibuat gathering antara beberapa staff."

Kemudian berkenaan dengan pelatihan dalam kebijakan serta prosedur perusahaaan atau training in company policies and procedures sudah sesuai dengan konsep Daly \& Moloney (2004:34) hal ini dikarenakan perusahaan CGV Cinemas melakukan pelatihan sesuai dengan prosedur serta kebijakan perusahaan dengan mengadakan pelatihan dalam learning \& development dalam bentuk CGV University yang sudah disesuaikan dengan standar dan prosedur dari CGV pusat.

Sebaiknya dalam meningkatkan pelatihan agar sesuai dengan kebijakan dan prosedur perusahaan, perusahaaan juga dapat melakukan kegiatan untuk memotivasi kerja karyawan bersamaan dengan pelatihan dengan metode simulasi.

Pernyataan ini diperkuat oleh Mangkunegara (2011:63) bahwa: "metode simulasi adalah suatu situasi atau peristiwa menciptakan bentuk realitas atau imitasi dari realitas."
Pada tahap planning menurut Daly \& Moloney (2004: 35), ada 3 poin yang harus diperhatikan. Pertama, siapa target audience yang dituju. Yang kedua, adalah untuk mengidentifikasi external customernya dan strategi renaming serta bagaimana CGV Cinemas melakukan rebranding marketing plan.

Sedangkan yang ketiga, adalah bagaimana perusahaan mengidentifikasi internal customernya dengan mengetahui apa saja strategi komunikasi internal untuk CGV Cinemas seperti perencanaan untuk pelatihan dan kampanye komunikasi apa yang dilakukan oleh CGV Cinemas untuk internal serta apa saja peraturan dan prosedur dari pelatihan di perusahaan.

Selanjutnya pada tahap terakhir yaitu tahap evaluasi, Pada poin evaluasi seluruh kampanye, upaya yang dilakukan dalam evaluasi kampanye masih belum sesuai hal ini dikarenakan CGV Cinemas menggabungkan evaluasi dengan kampanye komunikasi melalui tanya jawab pada saat pelaksanaan kampanye komunikasi dilakukan melalui sosialiasi tersebut namun tidak melakukan evaluasi kampanye komunikasi setelah melakukan kampanye komunikasi tersebut. Padahal menurut Daly \& Moloney (2004:35): "Banyak kesempatan untuk memperbaiki kampanye kampanye yang akan ter- 
lewatkan jika evaluasi tidak dilakukan sepanjang proses".

Sebaiknya, menurut peneliti CGV Cinemas memperbaiki evaluasi kampanye komunikasi dengan mengadakan riset untuk menghitung efektivitas kampanye melalui riset evaluatif agar dapat mengukur evaluasi terhadap program komunikasi yang dijalankan. Pernyataan ini diperkuat oleh Wasesa dan Macnamaraa (2013:258) bahwa riset evaluative digunakan untuk menghitung efektivitas sebuah kampanye.

Selain menggunakan riset evaluative, komunikasi kampanye dapat dievaluasi dengan menggunakan tingkatan evaluasi kampanye. Suatu kampanye komunikasi tidaklah efektif jika tidak diadakan evaluasi.

Kemudian evaluasi kampanye yang lainnya adalah media monitoring. Berkenaan dengan media monitoring $\mathrm{CGV}$ Cinemas, sudah dilakukan sesuai dengan konsep Daly \& Moloney (2004:35) dimana CGV Cinemas secara rutin melakukan media monitoring melalui platform untuk social media.

Dalam meningkatkan evaluasi kampanye melalui media monitoring ini, sebaiknya media monitoring ini dipertahankan dengan cara memanfaatkan platform yang digunakan dengan diukur berapa banyak followers yang dipunyai,matriks dari social media, tanggapan consumer dan juga berapa banyak orang yang mention di social media CGV Cinemas. Pernyataan ini diperkuat oleh Turner (2012) bahwa:

"The first category is quantitative, second category is qualitative. Quantitative tools measure data.Qualitative tools measures the sentiment behind the comment"

Selain melakukan monitoring melalui tools yang terdiri dari kategori quantitative dan qualitative, social media monitoring platforms dapat dimanfaatkan melalui Share Of Voice untuk memantau percakapan sehari-hari melalui platform yang digunakan dan juga dapat melihat percakapan melalui kata kunci unntuk melihat bagaimana customer melihat sentimen merek perusahaan. Pernyataan ini diperkuat oleh Breakenridge, (2012:42)

"Many social media monitoring platforms today enable you to track daily conversation across platforms unvovers your Share of Voice (SOV)."

Selanjutnya, pada poin evaluasi yang dilakukan saat ini dan setelah selesai, CGV Cinemas sudah melakukan kegiatan evaluasi pelatihan sesuai dengan konsep. Hal ini dapat dilihat bagaimana $\mathrm{CGV}$ Cinemas mengadakan pratest dan posttest untuk mengukur evaluasi sebelum melakukan pelatihan dan mengukur sesudah pelatihan. Pernyataan ini sesuai 
dengan konsep Daly \& Moloney (2004:35) bahwa: "Such staged evaluation allow any aspect of plan to be altered as the need for such change becomes evident"

Peneliti menyarankan, evaluasi pelatihan ini dipertahankan dengan cara membuat suatu indikator keberhasilan, tentunya indikator dalam hal ini merupakan alat pengukur bagi pencapaian dan dibutuhkan kriteria untuk mencapai indikator. Pernyataan ini diperkuat oleh Fauzi (2011:82) bahwa terdapat indikator yang harus memenuhi kriteria SMART, yaitu:

"Simple (sederhana), Measurable (dapat diukur), Attainable (dapat diterima), Reliable (dapat diandalkan), Time bound (mempunyai batasan waktu)."

Selain itu berkaitan dengan evaluasi yang dilakukan CGV Cinemas dengan melakukan focus group discussion dengan customer masih belum sesuai karena pada konsep Daly \& Moloney (2004:35) dijelaskan bahwa evaluasi dilakukan saat rebranding atau setelah selesai rebranding agar dapat melihat sudut pandang yang menyeluruh namun evaluasi yang dilakukan CGV Cinemas terhadap customer bersifat non formal dan tidak menyeluruh serta tidak mempunyai hasil yang terstruktur maka dari itu evaluasi tersebut tidak dapat dijadikan ukuran keberhasilan.

Peneliti menyarankan sebaiknya tahapan evaluasi dengan customer terkait rebranding dilakukan dengan menciptakan survey terkait kepuasan pelanggan atau customer satisfaction agar dapat mengukur evaluasi customer dengan lebih optimal, terstruktur dan efektif. Menurut Day (dalam Tjiptono,2008:24) menyatakan kepuasan atau ketidakpuasan pelanggan adalah respon pelanggan terhadap evaluasi ketidaksesuaian (disconfirmation).

\section{SIMPULAN}

Tahapan analisis meliputi beberapa tahap yaitu situation analysis yang terdiri dari market analysis, brand audit, opportunity identification selanjutnya tahap retain \& support.

Selanjutnya tahap neutralise terdiri dari mengidentifikasi elemen merek yang dapat dihilangkan serta new brand decision. Semua tahap sudah dilaksanakan. Lalu selanjutnya pada tahap retain \& support dilakukan dengan mempertahankan elemen merek dari konsep cultureplex .

Tahap perencanaan terdiri dari tahap target audience yang terdiri dari external dan internal. Internal customer adalah karyawan $C G V$ Cinemas. Selanjutnya dilanjutkan ke tahap external customer dimana pada tahapan ini terbagi menjadi 
dua yaitu renaming strategy dimana pada poin ini sudah sesuai dan pada poin rebranding marketing plan meskipun sudah dilakukan rebranding marketing plan yang terdiri dari beberapa elemen mix seperti pricing, product benefit dan product range dan integrated communication namun masih belum sesuai dengan konsep dikarenakan elemen mix dibuat dan ditentukan oleh perusahaan korea yaitu CJ Group dan integrated communication dibuat oleh tim rebranding task force padahal suatu elemen mix di dalam rebranding marketing plan merupakan kerangka berurutan.

Lalu selanjutnya pada tahap internal customer terdapat communication strategy dimana communication campaign yang belum optimal.

Pada tahap mengevaluasi seluruh kampanye terdapat evaluasi yang dilakukan dalam bentuk tanya jawab namun evaluasi tersebut dilakukan pada pelaksanaan sosialisasi dan CGV Cinemas tidak mengadakan evaluasi sesudah mengadakan kampanye komunikasi sehingga belum sesuai. Lalu selanjutnya evaluasi dilakukan media monitoring melalui social media CGV Cinemas dan sudah sesuai. Pada evaluasi yang sedang berlangsung dan telah dilaksanakan dilakukan dengan cara mengadakan evaluasi terkait pelatihan. Dan pada evaluasi selanjutnya melalui focus group discussion ke beberapa customer namun $f g d$ merupakan evaluasi non formal sehingga tidak menyeluruh sehingga belum sesuai.

\section{DAFTAR PUSTAKA}

Ariani, Wahyu., (2009), Manajemen Operasi Jasa. Graha Ilmu, Yogyakarta

Aaker, David., (1997), Manajemen Ekuitas Merek. ,Spektrum, Jakarta.

Breakenridge,. Deirdre., (2012). Social Media and Public Relations, FT.PRESS, New Jersey

Brown, Lyndon. (2008). Market Research and Analysis, Wildside Press, Rockville USA Callingham

Fauzi, I K., (2011), Mengelola Pelatihan Partisipatif. Alfabeta Anggota IKAPI, Bandung.

Gunawan, Imam., (2015), Metode Penelitian Kualitatif Teori dan Praktik, PT Bumi Aksara, Jakarta.

Hisrich, R.D., Peters. M.P .. dan Shepherd D.A. (2008). Kewirausahaan Edisi 7 Edisi Bahasa Indonesia, Salemba Empat, Jakarta

Kartajaya, Hermawan., (2010). Brand Operation The Official MIM Academy course book., Esensi Erlangga Group, Jakarta. 
Edutech, Tahun 17, Vol.17, No.1, Februari 2018

Kasali, R., (2003), Manajemen Public Relation

Pustaka Utama Grafiti, Jakarta.

Kelley, Larry D \& Donald W., Jugenheimer, (2008), Advertising Media Planning, A. Brand Managment Approach. M.E.Shape, Inc, New York.

Kotler,P., Keller, K., (2009). Manajemen Pemasaran. Vol.I, Ed. 12 , PT. Indeks, Jakarta

Kotler,P., Keller, K., (2009), Manajemen Pemasaran, Vol. II. Ed. 13, Erlangga, Jakarta.

Kotler, P., Armstrong, G., (2001). Prinsip -prinsip Pemasaran, Vol. 1, Ed. 18, Erlangga, Jakarta.

Kotler, P., Armstrong, G., 2008. Prinsipprinsip Pemasaran, Vol. 2, Ed. 12, Erlangga, Jakarta.

Nugroho J., Setiadi., (2003). Perilaku Konsumen (Konsep dan Implikasi) untuk Strategi dan Penelitian Pemasaran, Andi, Yogyakarta

Parente, D, E., Hutchinson K.S.L, (2015). Advertising Campaign: A Guide To Marketing Communication Plans, Ed.5, Cengage Learnin, Boston

Rakhmat, Jalaluddin., (2009), Metode
Penelitian Komunikasi, PT Remaja Rosdakarya, Bandung.

Sari, Christina, A, S,.(2017). Teknik Mengelola Produk \& Merek, PT. Gramedia Pustaka Utama, Jakarta.

Setiadi, Nugroho J, (2003) , Perilaku Konsumen, Kencana, Jakarta.

Sugiyono, (2009,) Memahami Penelitian Kualitatif. Alfabeta, Bandung.

Sugiyono, (2012). Metode Penelitian Kuantitatif Kualitatif dan $R \& D$, Alfabeta, Bandung.

Susanto., Hilmawan W., (2004), Power Branding, Membangun Merek. Unggul dan Organisasi Pendukungnya. PT Mizan Publika Jakarta, Jakarta.

Tjiptono, Fandy., (2008), Strategi Pemasaran, Edisi 3, Andi Offset, Yogyakarta.

Turner Jamie, (2012), How To Use Social Media Monitoring Tools. FTPress, New Jersey.

Wasesa, S. A., \& Macnamara, J., (2013), Strategi Public Relations. Ed.3, PT. Gramedia Pustaka Utama, Jakarta.

\section{Sumber E-Book}

Daly,A. and D.Moloney. (2004).“Managing 
corporate rebranding", Irish Marketing Review,Vol. 17 Nos 1/2,pp.30-6. Avaliableat: www.arrow.dit.ie/jouimriss/29/

(diakses 3 Maret 2017)

\section{Online :}

Fitria, P. A., (2018), Proses Rebranding Mal Grand Indonesia Oleh Departemen Marketing Communication PT. Grand Indonesia, Jurnal PRofesi Humas Vol.2, No. 2. Februari. 2018

Natasha, K. H., (2016), CORPORATE REBRANDING GRAMEDIA STORE Jurnal Edutech, Vol. 15, No.3, Oktober 2016 